\title{
Psychological Stress and Stressors Among Clinical Dental Students at Shiraz School of Dentistry, Iran
}

This article was published in the following Dove Press journal:

Advances in Medical Education and Practice

\section{Zahra Jowkar' \\ Maryam Masoumi ${ }^{2}$ \\ Hossein Mahmoodian ${ }^{3}$ \\ 'Oral and Dental Disease Research Center, Department of Operative Dentistry, School of Dentistry, Shiraz University of Medical Sciences, Shiraz, Iran; ${ }^{2}$ Department of Operative Dentistry, School of Dentistry, Shiraz University of Medical Sciences, Shiraz, Iran; ${ }^{3}$ Department of Medical Ethics, Shiraz University of Medical Sciences, Shiraz, Iran}

\begin{abstract}
Objective: The purpose of this study was to assess the level of psychological stress and the perceived stressors among the undergraduate clinical dental students of Shiraz School of Dentistry. Materials and Methods: This study was conducted during the second semester of the academic year 2018-2019 at Shiraz School of Dentistry, Shiraz University of Medical Sciences, Iran. The study group consisted of 150 dental clinical students. The participants were surveyed via the validated Depression, Anxiety, and Stress Scale (DASS-21) and the Dental Environment Stress (DES) questionnaires. One-way ANOVA, post hoc Tukey's test, repeated measure ANOVA, Holm-Sidak's test, and $t$-test were performed to analyze the data after the normality of the data was checked by Kolmogorov-Smirnov test. The P values of less than 0.05 were considered as statistically significant.

Results: No significant differences were observed among the dental students with different academic levels in terms of depression and anxiety scores $(\mathrm{P}=0.057$ and 0.154 , respectively). The lowest and highest stress scores were observed among the sixth- and fifth-year students, respectively ( $\mathrm{P}$ values $<0.05$ ). The scores of the stressors associated with the academic factors were significantly higher than those of the other domains $(\mathrm{P}<0.05)$ except for that of the clinical education domain $(\mathrm{P}=0.070)$. The females showed significantly higher DES scores ( $\mathrm{P}$ values $<0.05$ ).

Conclusion: The highest and lowest stress levels were observed among the fifth- and sixthyear students, respectively. The primary sources of stress were academic factors and clinical education. The females expressed higher levels of stress in certain areas of dental training.
\end{abstract} Keywords: dental students, risk factor, Shiraz School of Dentistry, stress

\section{Introduction}

Dental schools are reported to be highly demanding and stressful learning environments. ${ }^{1}$ Stress might result in various mental and physical problems leading to exhaustion as well as physical and mental illnesses. ${ }^{2}$ Furthermore, it results in diminished efficiency in learning. ${ }^{3}$ Recent studies have shown that studying dentistry can be extremely stressful for dentistry students who need to acquire diverse proficiencies such as theoretical knowledge, clinical skills, and interpersonal communication skills. ${ }^{4}$ Dentistry stressors could be classified into five areas: the living environment, personal characteristics, educational environment, academic factors, and clinical factors. ${ }^{4}$ It has been reported that dental students show considerable stress symptoms during their training. ${ }^{5}$ Moreover, dental students demonstrate higher levels of stress, depression, obsessive-compulsive disorders, and interpersonal sensitivity than the general population. ${ }^{1,6}$ A previous study showed that students in clinical years (fourth, fifth, and sixth) had higher levels of stress than those in
Correspondence: Zahra Jowkar

Oral and Dental Disease Research Center, Department of Operative Dentistry, School of Dentistry, Shiraz University of Medical Sciences, Shiraz, Iran

$\mathrm{Tel}+98-71-36263193$

Fax+98-7I-36280804

Email zahrajowkar66@gmail.com 
preclinical years. In addition, stress levels were higher in female students than their male counterparts. ${ }^{7}$ A previous study demonstrated that third-year students had the highest amount of stress among the students. ${ }^{8}$ Another study, however, found that final-year students showed the highest levels of stress and first-year students had the lowest levels of stress among the students. ${ }^{9}$

Divaris and Polychronopoulou reported that fourthyear dental students were concerned about their career prospects and the newly arrived students were greatly concerned about the little time of rest. ${ }^{10}$ Kumar et al examined the causes of stress among dental students in India and reported that the main causes of stress among the students were the exams, the academic assessment scores at the end of a busy day, and the professors' evaluation of their clinical performance. ${ }^{11}$ A systematic review demonstrated that exams, clinical performance, and professors were the key factors that induced stress among dental students. ${ }^{4}$ In another study, the main stressors of dental students were their exams, fear of failure, and concerns about completing the course requirements. ${ }^{11}$ Academic performance might be affected by the students' gender, ethnicity, stage of dental education, and the living environment. It has previously been shown that female and ethnic minority dental students had higher levels of stress. ${ }^{6,12,13}$ Moreover, since the move from preclinical to clinical years of dental education is reported to be highly stressful, it would also be informative to examine the relationship between stress and stage of education. ${ }^{14}$

If stress is not effectively tackled, it can lead to physical and psychological symptoms which can endanger the health of individuals. ${ }^{15}$ Persistent stress can impair the students' well-being leading to their diminished efficiency at work or learning, inability to continue working, difficulty to interact with their patients, and finally depersonalization. The problems associated with elevated levels of stress might finally deteriorate the students' academic achievements and reduce their career options. ${ }^{16}$ Therefore, assessing the stress levels and stressors among dental students can be helpful in terms of managing stress and its side effects. In this regard, the present research aimed to evaluate the stress levels and stressors of the dental environment among clinical dental students at Shiraz University of Medical Sciences.

\section{Methods}

The current study was carried out during the second semester of the academic year 2018-2019. It targeted the students of the third, fourth, fifth, and sixth years of education who were in the clinical stage at Shiraz School of Dentistry, Shiraz University of Medical Sciences, Iran. They entered the study via a convenience sampling method. The study was conducted on year 3-6 students since they begin their dentistry-specific studies in their third year.

This study was approved by the Medical Ethics Committee of Shiraz University of Medical Sciences (IR. SUMS.DENTA1.REC.1398.25) and all participants signed a written consent form before enrolling in the study. The questionnaire was accompanied by a cover letter containing the following elements: the objectives of the study, voluntary participation, and the confidentiality of the data. The total number of the students of the third, fourth, fifth, and sixth years of education who were in the clinical stage at Shiraz School of Dentistry, Shiraz University of Medical Sciences, Iran was 240. One hundred and fifty dental students $(62.5 \%$ of the total students who were in the clinical stage) were included in the present study.

To investigate the level of perceived stress in the dental environment, the short form of the Depression, Anxiety, and Stress Scale-21 (DASS-21) questionnaire was used. ${ }^{17}$ The DASS questionnaire was first developed by Lovibond and Lovibond. $^{18}$ The DASS-21 questionnaire which is a shortform version of the DASS measures the negative emotional states of depression, anxiety, and stress by the sum of the 7 corresponding questions. ${ }^{17}$ The questionnaire had 21 items which were rated on a 4-point Likert scale (from 0 (did not apply to me at all) to 3 (applied to me very much or most of the time)). The higher the grade, the higher the levels of stress. ${ }^{17}$ The final score for stress, anxiety, or depression was obtained by doubling the initial sum of the scales of the 7 corresponding questions because the DASS-21 (21 items) is a short-form version of the DASS (42 items). ${ }^{17}$ The cutoff scores for the severity labels of the DASS-21 have been demonstrated in Table $1 .{ }^{18}$ A printed Persian version of this questionnaire validated by Sahebi et al was used in this study. ${ }^{19}$

Table I The Cutoff Scores for the Severity Labels of the DASS-2 I Questionnaire $^{18}$

\begin{tabular}{|l|l|l|l|}
\hline Severity Label & Anxiety & Depression & Stress \\
\hline Normal & $0-7$ & $0-9$ & $0-14$ \\
Mild & $8-9$ & $10-13$ & $15-18$ \\
Moderate & $10-14$ & $14-20$ & $19-25$ \\
Severe & $15-19$ & $21-27$ & $26-33$ \\
Extremely severe & $20+$ & $28+$ & $34+$ \\
\hline
\end{tabular}


To assess the sources of stress associated with undergraduate dental studies and training, the Dental Environment Stress (DES) questionnaire was used. ${ }^{15}$ The DES questionnaire has been used as the most common tool for the assessment of stress among dental students. ${ }^{20}$ A printed Persian version of this questionnaire validated by Ramazani and Nazari was used in the current study. ${ }^{20}$ This questionnaire consisted of 32 items grouped under six stress-provoking domains related to the stressors associated with undergraduate dental training: academic efficiency ( 7 items), patient treatment ( 4 items), internal beliefs ( 4 items), academic factors ( 2 items), clinical education (11 items), and other items (4 items). ${ }^{20}$ The response to each item was rated on a 4-point Likert scale (1=not stressful, $2=$ =lightly stressful, $3=$ =moderately stressful, $4=$ =very stressful). The mean score was calculated for each item of the DES questionnaire. ${ }^{9,20}$ Moreover, the demographic information of the students including age, gender, academic year in dentistry, and marital status were collected.

For data analysis, the mean and standard deviation (SD) values of all groups were obtained using the SPSS software version 20.0 (IBM SPSS Statistics for Windows, Version 20.0. Armonk, NY: IBM Corp). The one-way ANOVA, post hoc Tukey's test, and $t$-test were performed to analyze the data after the normality of the data was checked based on the Kolmogorov-Smirnov test. The $\mathrm{P}$ values of less than 0.05 were considered as statistically significant.

\section{Results}

In total, 150 clinical dental students took part in the study (84 females and 66 males). The mean age of the respondents was $22.8 \pm 1.47$ years (ranging from 19 to 29 years old).

The normality assumption was held in all cases. To investigate the level of perceived stress in the dental environment, the DASS-21 questionnaire was used. The results of the mean depression, anxiety, and stress values according to the students' gender are presented in Table 2. According to the results of the $t$-test, no significant differences were found

Table 2 The Mean Depression, Anxiety, and Stress Scores According to the Students' Gender

\begin{tabular}{|l|l|l|l|}
\hline \multirow{2}{*}{$\begin{array}{l}\text { Gender (Number of } \\
\text { Participants) }\end{array}$} & \multicolumn{3}{|l|}{ DASS 2 I Scores } \\
\cline { 2 - 4 } & Depression & Anxiety & Stress \\
\hline Female (84) & $5.59 \pm 4.32$ & $4.53 \pm 3.71$ & $8.21 \pm 4.56$ \\
Male (66) & $5.63 \pm 4.18$ & $4.03 \pm 3.80$ & $7.51 \pm 4.80$ \\
P value & 0.0876 & 0.221 & 0.488 \\
\hline
\end{tabular}

between the two genders in terms of depression, anxiety, or stress scores ( $\mathrm{P}=0.876,0.221$, and 0.488 , respectively).

Of the 150 dental students who participated in this study, 132 were single and 18 were married. The results of depression, anxiety, and stress values according to the students' marital status are presented in Table 3. According to the results of the $t$-test, there were no significant differences between single and married dental students in terms of depression, anxiety, or stress scores $(\mathrm{P}=0.387,0.182$, and 0.453 , respectively).

Of the 150 dental students who participated in this study, 31 were third-year, 41 were fourth-year, 38 were fifth-year, and 40 were final-year dental students. The results of the mean depression, anxiety, and stress values according to the students' academic level are presented in Table 4. According to the results of the one-way ANOVA, there were no significant differences among the dental students with different academic levels in terms of depression and anxiety scores ( $\mathrm{P}=0.057$ and 0.154 , respectively). However, the stress scores were significantly different among different levels of education $(\mathrm{P}=0.025)$. The highest stress score was observed among the fifth-year students ( $9.13 \pm 5.11)$ followed by the third-year $(8.71 \pm 4.22)$, fourthyear $(8.04 \pm 4.35)$, and sixth-year $(5.97 \pm 4.43)$ students.

The DES questionnaire was also used in this research. The mean scores of the 6 main domains of the DES questionnaire are presented in Table 5.

In general, the results of the repeated measure ANOVA with a Greenhouse-Geisser correction revealed a significant difference among the scores of various domains $(\mathrm{P}<0.001)$. The Holm-Sidak's test was used as the post hoc test for multiple comparisons. As shown in Table 5, the scores of the stressors associated with the academic factors were significantly higher than those of the other domains $(\mathrm{P}<0.05)$ except for that of the clinical education domain $(\mathrm{P}=0.070)$. Moreover, the scores of the stressors associated with the internal beliefs $(1.89 \pm 0.69)$ were significantly lower than those of the other domains $(\mathrm{P}<0.001$ in domains $1-5$ and $\mathrm{P}=0.002$ in domain 6$)$.

Table 3 The Mean Depression, Anxiety, and Stress Scores According to the Students' Marital Status

\begin{tabular}{|l|l|l|l|}
\hline \multirow{2}{*}{$\begin{array}{l}\text { Marital Status (Number } \\
\text { of Participants) }\end{array}$} & \multicolumn{3}{|l|}{ DASS 2 I Scores } \\
\cline { 2 - 4 } & Depression & Anxiety & Stress \\
\hline Single (132) & $5.73 \pm 4.30$ & $4.16 \pm 3.65$ & $7.94 \pm 4.7$ I \\
Married (18) & $4.72 \pm 3.8$ I & $5.47 \pm 4.37$ & $7.61 \pm 4.49$ \\
P value & 0.387 & 0.182 & 0.453 \\
\hline
\end{tabular}


Table 4 The Mean Depression, Anxiety, and Stress Scores According to the Students' Academic Level

\begin{tabular}{|l|l|l|l|}
\hline $\begin{array}{l}\text { Academic Level } \\
\text { (Number of }\end{array}$ & \multicolumn{3}{|l|}{ DASS 2I Scores } \\
\cline { 2 - 4 } Participants) & Depression & Anxiety & Stress \\
\hline Third-year (3I) & $6.00 \pm 4.75$ & $4.77 \pm 4.55$ & $8.71 \pm 4.22$ \\
Fourth-year (4I) & $6.12 \pm 3.84$ & $4.27 \pm 3.22$ & $8.04 \pm 4.35$ \\
Fifth-year (38) & $6.39 \pm 4.74$ & $5.1 I \pm 4.37$ & $9.13 \pm 5.11$ \\
Sixth-year (40) & $4.05 \pm 3.4 I$ & $3.25 \pm 3.22$ & $5.97 \pm 4.43$ \\
P value & 0.057 & 0.154 & $0.025^{*}$ \\
\hline
\end{tabular}

Note: *Significant.

Table 5 The Mean Scores of the 6 Domains of the DES Questionnaire

\begin{tabular}{|l|l|}
\hline Domains & Scores (Minimum/Maximum) \\
\hline I-Academic efficiency & $\begin{array}{l}2.25 \pm 0.60^{\mathrm{B}} \\
(1.00 / 4.00)\end{array}$ \\
\hline II-Patient treatment & $\begin{array}{l}2.22 \pm 0.67^{\mathrm{B}} \\
(1.00 / 4.00)\end{array}$ \\
\hline III-Internal beliefs & $\begin{array}{l}1.89 \pm 0.69^{\mathrm{C}} \\
(1.00 / 4.00)\end{array}$ \\
\hline IV-Academic factors & $2.50 \pm 0.96^{\mathrm{A}}$ \\
& $(1.00 / 4.00)$ \\
\hline V-Clinical education & $2.30 \pm 0.65^{\mathrm{AB}}$ \\
& $(1.00 / 4.00)$ \\
\hline VI-Other items & $2.16 \pm 0.72^{\mathrm{B}}$ \\
& $(1.00 / 4.00)$ \\
\hline Total & $2.22 \pm 0.5 \mathrm{I}$ \\
& $(1.03 / 4.00)$ \\
\hline
\end{tabular}

Notes: The domains marked with the same uppercase letter are not statistically significantly different from each other. The domains marked with different uppercase letters are statistically significantly different from each other.

The results of the mean scores of the DES domains according to the academic level of the participants are also presented in Table 6 .

The ANOVA revealed that there were significant differences among the students with different academic levels in terms of mean DES scores $(\mathrm{P}<0.001)$. In general, the sixthyear students had significantly lower scores compared to the third-, fourth-, and fifth-year students $(\mathrm{P}=0.031, \mathrm{P}=0.036$, and $\mathrm{P}<0.001$, respectively).

According to the post hoc Tukey's test, significant differences were observed among the students with different academic levels in terms of the stressors related to academic efficiency, patient treatment, and clinical education $(\mathrm{P}<0.001, \mathrm{P}=0.030$, and $\mathrm{P}<0.001$, respectively).
However, there were no significant differences among the students with different levels of education in terms of the stressors related to internal beliefs, academic factors, and other items ( $\mathrm{P}=0.949, \mathrm{P}=0.084$, and $\mathrm{P}=0.141$, respectively).

Moreover, the $t$-test was applied to compare the two genders in terms of the DES scores in the 6 domains. The results are presented in Table 7 . In total, there were significant differences between male and female students in terms of the DES scores $(\mathrm{P}=0.001)$.

The DES scores of the stressors related to patient treatment, academic factors, and clinical education were significantly higher in females than in males $(\mathrm{P}=0.002$, $\mathrm{P}<0.001$, and $\mathrm{P}<0.001$, respectively).

Furthermore, the $t$-test was applied to compare the DES scores of the students with different marital status. The results are shown in Table 8. In total, there were no significant differences between single and married dental students in terms of mean DES scores $(\mathrm{P}=0.058)$. The mean DES scores of the stressors related to patient treatment were significantly higher in married students than in single ones $(\mathrm{P}=0.021)$.

\section{Discussion}

Dental undergraduate training is a challenging learning experience. To qualify as responsible dental professionals, students are expected to learn both the theoretical and technical aspects of the dental curriculum in addition to dealing with patients. Moreover, it has previously been reported that dental students experience higher levels of stress compared to medical students which is justified by the additional psychomotor skills needed in dentistry. ${ }^{21}$ As a result, many researchers have been interested in studying stress levels in undergraduate dental students using a wide range of methods from self-reported questionnaires (such as the Perceived Stress Scale and the Dental Environment Stress (DES) questionnaire) to such methods as examining biological markers. ${ }^{9,22,23}$ Many researchers have used the DES questionnaire to identify the sources of stress in dental students. Some studies have used the mean score for each item from the DES questionnaire and others have used the mean scores for the categories that emerged from DES factor analysis to report the causes of stress. ${ }^{6,10,11}$ Several studies have investigated various sources of stress in dental students. ${ }^{1,2,46}$ The current study is the first to explore the psychological well-being as well as the stress-provoking factors among Iranian dental students. Iranian dental education is provided through dental schools and encompasses a six-year study program. The first and second years are 
Table 6 The Mean Scores of the 6 Domains of the DES Questionnaire According to the Academic Level of the Participants

\begin{tabular}{|c|c|c|c|c|c|}
\hline \multirow[t]{2}{*}{ Domains } & $\begin{array}{l}\text { Third-Year (Number } \\
\text { of Participants = } 3 I \text { ) }\end{array}$ & $\begin{array}{l}\text { Fourth-Year (Number } \\
\text { of Participants }=4 I \text { ) }\end{array}$ & $\begin{array}{l}\text { Fifth-Year (Number } \\
\text { of Participants }=38 \text { ) }\end{array}$ & $\begin{array}{l}\text { Sixth-Year (Number } \\
\text { of Participants }=40 \text { ) }\end{array}$ & \multirow[t]{2}{*}{$P$ value } \\
\hline & (Minimum/Maximum) & (Minimum/Maximum) & (Minimum/Maximum) & (Minimum/Maximum) & \\
\hline I-Academic efficiency & $\begin{array}{l}2.34 \pm 0.50^{\mathrm{A}} \\
(1.00 / 3.29)\end{array}$ & $\begin{array}{l}2.28 \pm 0.62^{\mathrm{A}} \\
(1.00 / 3.57)\end{array}$ & $\begin{array}{l}2.51 \pm 0.54^{\mathrm{A}} \\
(1.43 / 4.00)\end{array}$ & $\begin{array}{l}1.89 \pm 0.54^{B} \\
(1.00 / 3.00)\end{array}$ & $<0.001 *$ \\
\hline II-Patient treatment & $\begin{array}{l}2.07 \pm 0.72^{\mathrm{AB}} \\
(1.00 / 3.50)\end{array}$ & $\begin{array}{l}2.29 \pm 0.54^{\mathrm{AB}} \\
(1.00 / 3.25)\end{array}$ & $\begin{array}{l}2.45 \pm 0.78^{A} \\
(1.00 / 4.00)\end{array}$ & $\begin{array}{l}2.04 \pm 0.64^{B} \\
(1.00 / 3.25)\end{array}$ & $0.030 *$ \\
\hline III-Internal beliefs & $\begin{array}{l}1.89 \pm 0.73^{\mathrm{A}} \\
(1.00 / 3.75)\end{array}$ & $\begin{array}{l}1.86 \pm 0.65^{\mathrm{A}} \\
(1.00 / 3.50)\end{array}$ & $\begin{array}{l}1.94 \pm 0.76^{\mathrm{A}} \\
(1.00 / 4.00)\end{array}$ & $\begin{array}{l}1.87 \pm 0.65^{\mathrm{A}} \\
(1.00 / 3.25)\end{array}$ & 0.949 \\
\hline IV-Academic factors & $\begin{array}{l}2.56 \pm 1.07^{\mathrm{A}} \\
(1.00 / 4.00)\end{array}$ & $\begin{array}{l}2.46 \pm 0.88^{\mathrm{A}} \\
(1.00 / 4.00)\end{array}$ & $\begin{array}{l}2.78 \pm 0.97^{\mathrm{A}} \\
(1.00 / 4.00)\end{array}$ & $\begin{array}{l}2.22 \pm 0.89^{A} \\
(1.00 / 4.00)\end{array}$ & 0.084 \\
\hline V-Clinical education & $\begin{array}{l}2.36 \pm 0.51^{\mathrm{AB}} \\
(1.45 / 3.27)\end{array}$ & $\begin{array}{l}2.27 \pm 0.54^{B} \\
(1.27 / 3.73)\end{array}$ & $\begin{array}{l}2.71 \pm 0.66^{A} \\
(1.09 / 4.00)\end{array}$ & $\begin{array}{l}1.91 \pm 0.61^{C} \\
(1.00 / 3.64)\end{array}$ & $<0.00 I^{*}$ \\
\hline VI-Other items & $\begin{array}{l}2.24 \pm 0.6^{\mathrm{A}} \\
(1.00 / 3.25)\end{array}$ & $\begin{array}{l}2.24 \pm 0.66^{\mathrm{A}} \\
(1.00 / 4.00)\end{array}$ & $\begin{array}{l}2.24 \pm 0.79^{A} \\
(1.00 / 4.00)\end{array}$ & $\begin{array}{l}1.93 \pm 0.73^{\mathrm{A}} \\
(1.00 / 3.00)\end{array}$ & 0.141 \\
\hline Total & $\begin{array}{l}2.26 \pm 0.4^{\mathrm{A}} \\
(1.4 \mathrm{I} / 3.22)\end{array}$ & $\begin{array}{l}2.23 \pm 0.45^{\mathrm{A}} \\
(1.38 / 3.28)\end{array}$ & $\begin{array}{l}2.48 \pm 0.53^{\mathrm{A}} \\
(1.44 / 4.00)\end{array}$ & $\begin{array}{l}1.94 \pm 0.50^{B} \\
(1.03 / 2.94)\end{array}$ & $<0.001 *$ \\
\hline
\end{tabular}

Notes: *Significant. The domains marked with the same uppercase letter are not statistically significantly different from each other. The domains marked with different uppercase letters are statistically significantly different from each other.

Table 7 The Mean Scores of the 6 Domains of the DES Questionnaire According to the Participants' Gender

\begin{tabular}{|l|l|l|l|}
\hline Domains & Male & Female & P-value \\
\hline I-Academic efficiency & $2.17 \pm 0.65^{\mathrm{A}}$ & $2.31 \pm 0.55^{\mathrm{A}}$ & 0.174 \\
II-Patient treatment & $2.03 \pm 0.73^{\mathrm{B}}$ & $2.37 \pm 0.6 \mathrm{I}^{\mathrm{A}}$ & $0.002^{*}$ \\
III-Internal beliefs & $1.84 \pm 0.76^{\mathrm{A}}$ & $1.94 \pm 0.62^{\mathrm{A}}$ & 0.377 \\
IV-Academic factors & $2.19 \pm 0.88^{\mathrm{B}}$ & $2.74 \pm 0.96^{\mathrm{A}}$ & $0.000^{*}$ \\
V-Clinical education & $2.04 \pm 0.67^{\mathrm{B}}$ & $2.50 \pm 0.56^{\mathrm{A}}$ & $0.000^{*}$ \\
VI-Other items & $2.08 \pm 0.74^{\mathrm{A}}$ & $2.22 \pm 0.70^{\mathrm{A}}$ & 0.235 \\
Total & $2.06 \pm 0.56^{\mathrm{B}}$ & $2.35 \pm 0.43^{\mathrm{A}}$ & $0.00 I^{*}$ \\
\hline
\end{tabular}

Notes: *Significant. The domains marked with the same uppercase letter are not statistically significantly different from each other. The domains marked with different uppercase letters are statistically significantly different from each other.

Table 8 The Mean Scores of the 6 Domains of the DES Questionnaire According to the Participants' Marital Status

\begin{tabular}{|l|l|l|l|}
\hline Domains & Single & Married & P-value \\
\hline I-Academic efficiency & $2.22 \pm 0.61^{\mathrm{A}}$ & $2.47 \pm 0.43^{\mathrm{A}}$ & 0.100 \\
II-Patient treatment & $2.17 \pm 0.68^{\mathrm{B}}$ & $2.57 \pm 0.67^{\mathrm{A}}$ & $0.021^{*}$ \\
III-Internal beliefs & $1.89 \pm 0.7 \mathrm{I}^{\mathrm{A}}$ & $1.90 \pm 0.54^{\mathrm{A}}$ & 0.951 \\
IV-Academic factors & $2.48 \pm 0.98^{\mathrm{A}}$ & $2.64 \pm 0.80^{\mathrm{A}}$ & 0.515 \\
V-Clinical education & $2.27 \pm 0.65^{\mathrm{A}}$ & $2.54 \pm 0.58^{\mathrm{A}}$ & 0.089 \\
VI-Other items & $2.12 \pm 0.74^{\mathrm{A}}$ & $2.40 \pm 0.52^{\mathrm{A}}$ & 0.124 \\
Total & $2.19 \pm 0.52^{\mathrm{A}}$ & $2.44 \pm 0.40^{\mathrm{A}}$ & 0.058 \\
\hline
\end{tabular}

Notes: *Significant. The domains marked with the same uppercase letter are not statistically significantly different from each other. The domains marked with different uppercase letters are statistically significantly different from each other. spent on basic science courses. Dental preclinical courses are offered primarily in the third year, while clinical work is covered in the fourth, fifth, and sixth years.

This study assessed the psychological well-being of 150 dental students at Shiraz School of Dentistry using the DASS-21 questionnaire. The results of this study indicated that the dental students at Shiraz School of Dentistry experienced normal levels of psychological distress. However, a previous study demonstrated that dental students experienced moderate stress in the educational environment which was attributed to the highly demanding and stressful learning environments of dental schools. ${ }^{24}$ Moreover, the levels of depression, anxiety, and stress of the students in this study were almost half of those in Arabian dental students as found in a previous study. ${ }^{25}$

According to the findings of the DASS-21, the highest stress score was observed among the fifth-year students followed by the third-, fourth-, and sixth-year students. Neither gender nor marital status had a significant effect on depression, anxiety, and stress values. Moreover, there were no significant differences among the dental students with different academic levels in terms of depression and anxiety scores.

In the current study, the DES questionnaire was used to assess the sources of stress among the dental students. This 
questionnaire consists of 38 items related to the stressors associated with undergraduate dental training. In the present study, the scores of the stressors associated with academic factors and clinical education were higher than those of the other domains. This finding indicates that the atmosphere created by the professors in the clinical setting along with the criticism the students received from the faculty members in the presence of the patient was among the factors that played an important role in the creation of stress for the dental students. However, the statistically significant relationship among different domains of the DES questionnaire in the current study might be due to the relatively large sample size (150). Moreover, in all 6 domains of the DES questionnaire, the fifth-year dental students showed higher DES scores compared to the third-, fourth-, and sixth-year students. Moreover, the final-year dental students showed lower mean DES scores in almost all domains compared to the other students. This finding may be due to the much higher number of clinical courses offered to fifth-year dental students compared to those offered to the other students. The fifth-year students are mainly concerned about the accuracy of clinical decisions that causes stress during clinical practice. ${ }^{26}$ The stress reduction in the sixth-year students compared with the fifth-year students in almost all domains is potentially due to the fact that final-year students have obtained more experience and skills in clinical work. Furthermore, as the results revealed, the third-year students had the second highest stress scores. This might be attributed to the high levels of psychological distress that students experience in the transition from preclinical to clinical training.

In line with the findings of the present study, a previous study that investigated longitudinal stress in dental students reported an increase in their stress levels compared with their first-year stress levels. ${ }^{27}$ However, a previous study demonstrated that third-year students had the highest amount of stress compared to the other students. ${ }^{8}$ Another longitudinal study demonstrated that the stress levels in dental students increased in the last year of their education compared to those of their first year. ${ }^{9}$ The differences in the results of the studies may be justified by the differences in the educational systems of dental schools.

Another finding of the present study was that females had higher DES scores for patient treatment, academic factors, and clinical education. It is known that women in the general population show a higher risk of depression and anxiety than men which might be related to their psychological makeup and their greater inclination to express their feelings and thoughts. ${ }^{28}$ Some studies have found differences in stress levels between men and women, while others have not. ${ }^{6,10,29,30}$ There are differences in how different genders deal with stress, with females being more vocal in reporting and speaking about stress. ${ }^{31}$ The following factors have previously been found to evoke greater stress among female students and have been supported by the current survey: lack of confidence to be a successful student and to become a successful dentist, fear of failure, examinations, and grades. ${ }^{32}$ Lack of self-confidence to be a successful dentalstudent and lack of self-confidence to be a successful dentist are among the items which have been evaluated in the internal belief domain of the DES questionnaire. The students' fears of failing the courses and the examinations are among the items which have been evaluated in the academic performance domain of the DES questionnaire. Female students also seemed more concerned about financial responsibilities. ${ }^{32}$

In this study, no significant differences were found between single and married dental students in terms of the mean DES scores. While some researchers suggest that marriage and raising children during academic education years can be a major stressor, others have reported that being single is a stress factor. ${ }^{30,33}$ The reason for the inconsistency between the results can be the differences in the sample sizes of the married group in different studies, the differences in family conditions, and the spiritual support that married students receive from their partners.

According to the results of this study, the third- and fifth-year dental students need more attention and support. Stress reduction has a direct relationship with the mental health status of individuals and is effective in promoting their performance. Therefore, to reduce stress in the dental environment, several measures which might play a role in stress management including reviewing educational programs, modifying student evaluation methods, enhancing the quality of counseling programs, implementing studentcentered academic policies, encouraging the students to participate in sports programs, and providing the students with the necessary entertainment facilities should be taken into account. The probable role of each mentioned measure for stress reduction in the dental environment should be evaluated in future studies. In this regard, a stress reduction program needs to be implemented at the Shiraz School of Dentistry. Moreover, female students experience 
more stress according to the results of the present study and thus need special attention for stress reduction.

Although some of the highly rated stressors appear to be inherent in professional education and prevalent in diverse dental educational settings, a modern dental school should manage potential stress sources effectively and thus promote the educational and professional well-being of the dental undergraduates.

This study has some limitations that need to be considered when interpreting the findings. The results from the present study are based on a cross-sectional descriptive study which was conducted on a limited sample size. Only one dental school (Shiraz, Iran) was evaluated in the present study. Further investigations on greater populations of dental students including the students of public and private dental schools in other dental institutions need to be done as well.

\section{Conclusion}

Dental students displayed moderate levels of psychological distress and moderate to medium stress scores. The highest and lowest stress levels were observed among the fifth- and sixth-year students, respectively. The primary sources of stress for the dental students at Shiraz University of Medical Sciences were academic factors and clinical education. Females expressed higher levels of stress in certain areas of dental training.

\section{Acknowledgments}

The authors thank the Vice-Chancellery of Research, Shiraz University of Medical Sciences for supporting this research (Number: 1397-01-03-18920). This article is based on Dr. Maryam Masoumi's thesis. The authors also thank Dr. Mehrdad Vossoughi for the statistical analysis. The authors also thank Dr. Arash Moradi for editorial assistance.

\section{Disclosure}

The authors report no conflicts of interest in this work.

\section{References}

1. Piazza-Waggoner CA, Cohen LL, Kohli K, Taylor BK. Stress management for dental students performing their first pediatric restorative procedure. J Dent Edu. 2003;67(5):542-548.

2. Goldstein MB. Interpersonal support and coping among first-year dental students. J Dent Edu. 1980;44(4):202-205.

3. Morse Z, Dravo U. Stress levels of dental students at the Fiji School of Medicine. Eur J Dent Edu. 2007;11(2):99-103. doi:10.1111/j.16000579.2007.00435.x

4. Alzahem A, Van der Molen H, Alaujan A, Schmidt H, Zamakhshary M. Stress amongst dental students: a systematic review. Eur J Dent Edu. 2011;15(1):8-18. doi:10.1111/j.1600-0579.2010.00640.x
5. Newbury-Birch D, Lowry R, Kamali F. The changing patterns of drinking, illicit drug use, stress, anxiety and depression in dental students in a UK dental school: a longitudinal study. $\mathrm{Br}$ Dent $J$. 2002;192(11):646-649. doi:10.1038/sj.bdj.4801448

6. Sanders A, Lushington K. Sources of stress for Australian dental students. J Dent Edu. 1999;63(9):688-697.

7. Halboub E, Alhajj MN, AlKhairat AM, Sahaqi AM, Quadri MFA. Perceived stress among undergraduate dental students in relation to gender, clinical training and academic performance. Acta Stomatol Croat. 2018;52(1):37-45. doi:10. $15644 /$ asc $52 / 1 / 6$

8. Alzahem AM, Van der Molen HT, De Boer BJ. Effect of year of study on stress levels in male undergraduate dental students. Adv Med Educ Pract. 2013;4:217-222. doi:10.2147/AMEP.S46214

9. Silverstein ST, Kritz-Silverstein D. A longitudinal study of stress in first-year dental students. J Dent Edu. 2010;74(8):836-848.

10. Polychronopoulou A, Divaris K. Perceived sources of stress among Greek dental students. J Dent Edu. 2005;69(6):687-692.

11. Kumar S, Dagli R, Mathur A, Jain M, Prabu D, Kulkarni S. Perceived sources of stress amongst Indian dental students. Eur $J$ Dent Edu. 2009;13(1):39-45. doi:10.1111/j.1600-0579.2008. 00535.x

12. Lloyd C, Musser LA. Psychiatric symptoms in dental students. J Nerv Ment Dis. 1989;177:61-69. doi:10.1097/00005053-1989 02000-00001

13. Yap A, Bhole S, Teo C. A cross-cultural comparison of perceived sources of stress in the dental school environment. J Dent Edu. 1996;60(5):459-464.

14. Alhajj M, Khader Y, Murad A, et al. Perceived sources of stress amongst dental students: a multicountry study. Eur J Dent Educ. 2018;22(4):258-271. doi:10.1111/eje.2018.22.issue-4

15. Garbee WH, Zucker SB, Selby GR. Perceived sources of stress among dental students. J Am Dent Assoc. 1980;100(6):853-857. doi:10.14219/jada.archive.1980.0279

16. Schmitter M, Liedl M, Beck J, Rammelsberg P. Chronic stress in medical and dental education. Med Teach. 2008;30(1):97-99. doi: 10.1080/01421590701769571

17. Basudan S, Binanzan N, Alhassan A. Depression, anxiety and stress in dental students. Int J Med Educ. 2017;8:179-186. doi:10.5116/ ijme.5910.b961

18. Lovibund S, Lovibund P. Manual for the Depression Anxiety Stress Scales. Sydney: Psychology Foundation; 1995.

19. Sahebi A, Asghari MJ, Salari R. Validation of depression anxiety and stress scale (DASS-21) for an Iranian population. J Iran Psychol. 2005;4:299-313.

20. Ramazani N, Nazari A. Dental environmental stress among clinical dentistry students in Zahedan School of Dentistry. Iran J Med Edu. 2013;13(9):753-765.

21. Murphy RJ, Gray SA, Sterling G, Reeves K, DuCette J. A comparative study of professional student stress. J Dent Edu. 2009;73(3):328-337.

22. Pau A, Croucher R. Emotional intelligence and perceived stress in dental undergraduates. J Dent Edu. 2003;67(9):1023-1028.

23. Ng V, Koh D, Mok B, Chia S-E, Lim L-P. Salivary biomarkers associated with academic assessment stress among dental undergraduates. J Dent Edu. 2003;67(10):1091-1094.

24. Elani HW, Allison PJ, Kumar RA, Mancini L, Lambrou A, Bedos C. A systematic review of stress in dental students. J Dent Edu. 2014;78 (2):226-242.

25. Aboalshamat K, Hou X-Y, Strodl E. Psychological well-being status among medical and dental students in Makkah, Saudi Arabia: a cross-sectional study. Med Teach. 2015;37(sup1):S75-S81. doi:10.3109/ 0142159X.2015.1006612

26. Manolova MS, Stefanova VP, Panayotov IV, et al. Perceived sources of stress in fifth year dental students-a comparative study. Folia Med. 2012;54(2):52-59. doi:10.2478/v10153-011-0089-3 
27. Gorter R, Freeman R, Hammen S, Murtomaa H, Blinkhorn A, Humphris G. Psychological stress and health in undergraduate dental students: fifth year outcomes compared with first year baseline results from five European dental schools. Eur J Dent Edu. 2008;12(2):61-68. doi:10.1111/j.1600-0579.2008.00468.x

28. Kessler RC, Berglund P, Demler O, et al. The epidemiology of major depressive disorder: results from the National Comorbidity Survey Replication (NCS-R). JAMA. 2003;289(23):3095-3105. doi:10.1001/ jama.289.23.3095

29. Guthrie E, Black D, Bagalkote H, Shaw C, Campbell M, Creed F. Psychological stress and burnout in medical students: a five-year prospective longitudinal study. J R Soc Med. 1998;91(5):237-243. doi: $10.1177 / 014107689809100502$
30. Sugiura G, Shinada K, Kawaguchi Y. Psychological well-being and perceptions of stress amongst Japanese dental students. Eur J Dent Edu. 2005;9(1):17-25. doi:10.1111/j.1600-0579.2004.00352.x

31. Naidu RS, Adams JS, Simeon D, Persad S. Sources of stress and psychological disturbance among dental students in the West Indies. J Dent Edu. 2002;66(9):1021-1030.

32. Westerman GH, Grandy T, Ocanto R, Erskine C. Perceived sources of stress in the dental school environment. J Dent Edu. 1993;57 (3):225-231.

33. Lovibond PF, Lovibond SH. The structure of negative emotional states: comparison of the Depression Anxiety Stress Scales (DASS) with the Beck depression and anxiety inventories. Behav Res Ther. 1995;33(3):335-343. doi:10.1016/0005-7967(94)00075-U

\section{Publish your work in this journal}

Advances in Medical Education and Practice is an international, peerreviewed, open access journal that aims to present and publish research on Medical Education covering medical, dental, nursing and allied health care professional education. The journal covers undergraduate education, postgraduate training and continuing medical education including emerging trends and innovative models linking education, research, and health care services. The manuscript management system is completely online and includes a very quick and fair peer-review system. Visit http://www.dovepress.com/testimonials.php to read real quotes from published authors. 